\title{
Rhinovirus and COPD airway epithelium
}

\author{
Nicole Owuor ${ }^{1}$, Nisha Nalamala ${ }^{1}$, Joao Antonio Gimenes Jr ${ }^{1}$ and Uma S. Sajjan ${ }^{1,2 *}$ \\ ${ }^{1}$ Department of Thoracic Surgery and Medicine, Temple University, Philadelphia, PA, USA \\ ${ }^{2}$ Department of Physiology, Temple University, Philadelphia, PA, USA
}

\begin{abstract}
Chronic Obstructive Pulmonary Disease (COPD) is characterized by irreversible airflow limitation. It is a global disease and expected to be the third leading cause of death. Respiratory exacerbations are associated with increased mortality and morbidity in this patient population. Respiratory viruses were isolated from at least 30 to $50 \%$ of the infectious respiratory COPD exacerbations with rhinovirus being most commonly isolated pathogen. Although rhinovirus does not cause airway epithelial damage like influenza and other respiratory viruses, it may further impair innate immunity of airway epithelium, which is the first line of defense in the lungs. This may increase susceptibility to secondary bacterial infections leading to progression of lung disease. Currently, there are no therapies available to treat rhinovirus infection in COPD and therefore understanding the mechanisms underlying RV pathogenesis in COPD is essential to identify molecular target to develop new therapeutic strategies. Quercetin, a plant polyphenol, which modulates innate immunity and effectively blocks viral replication may be useful in treating rhinovirus associated COPD exacerbations.
\end{abstract}

\section{Introduction}

Chronic Obstructive Pulmonary Disease (COPD) is a progressive disease characterized by irreversible airflow limitation. Patients with COPD experience symptoms including coughing with excessive mucus production, shortness of breath, and chest tightness. These symptoms sre exacerbated by viral and/or bacterial infections and other environmental factors. At least $70 \%$ of the exacerbations are due to respiratory infections, out of which 30 to $50 \%$ are associated with viruses. Rhinoviruses (RV) are one of the most commonly associated viruses with viral-related COPD exacerbations. RV causes self-limiting upper respiratory tract infection in healthy individuals. However, in COPD airways, RV infection is associated with persistent lung inflammation and airflow obstruction [1,2]. Additionally, RV also increases the risk for acquiring secondary bacterial infections [3] indicating that $\mathrm{RV}$ can impair lung innate immune mechanisms in patients with COPD.

\section{Rhinovirus}

RVs are non-enveloped viruses with single stranded positive strand RNA genome. There are over 150 serotypes of RV categorized phylogenetically into species $\mathrm{A}, \mathrm{B}$, and $\mathrm{C}$ [4]. Majority of the RV-A and RV-B bind to intracellular adhesion molecule 1 (ICAM-1), and the remaining bind to Low Density Lipoprotein Receptor (LDLR) family members $[5,6]$. Human cadherin family member 3 was recently identified as a receptor for RV-C [7]. RV-A and RV-B enter the cells by receptor-mediated endocytosis followed by uncoating to release the genome into the cytoplasm, where the virus replicates [1]. The entry and uncoating mechanism for RV-C is not well-known. Compared to RV-A and RV-B, RV-C is associated with severe lung disease in patients with chronic lung disease [8].

\section{Airway epithelium}

The primary target for RV infection is airway epithelium that lines the conductive airways. RV, which was thought to cause only upper respiratory tract infections, was also detected in ciliated cells of lower airways [9]. RV infects small proportion of ciliated cells in both and upper and lower airways. However, experimental evidence indicate that the basal cells of airway epithelium are more amenable to RV infection than ciliated cells [10]. Basal cell hyperplasia and leaky airway epithelium which can potentially expose basal cells are some of the features that are found in COPD airways [11,12] and this may increase susceptibility to RV infection. Since RV does not cause significant cell death, differences in the host immune responses are thought to be responsible for variable symptoms. Airway epithelial cells responds to $\mathrm{RV}$ infection by producing chemokines and growth factors to recruit other innate immune cells, which in addition to contributing to local inflammation and cold symptoms may also aid viral clearance and resolution of inflammation at later stages of infection. In addition, airway epithelial cells also express type I interferons, which can induce interferon-stimulated genes that inhibit viral replication. Therefore, we believe that appropriate airway epithelial responses are crucial in determining the viral clearance and resolution of inflammation following RV infection.

Previously, we have shown that mucociliary airway epithelial cell cultures established from COPD airway progenitor cells show goblet cell hyperplasia and produce more C-X-C chemokines under unstimulated conditions compared to similarly cultured airway progenitor cells from healthy non-smokers $[13,14]$. Expression of CXC-chemokine, IL-8 was partially due to attenuated activation of FOXO3A and persistent activation of EGF receptor in COPD airway epithelial cells [14]. Additionally, COPD airway epithelial cell cultures also show evidence of epithelial to mesenchymal transition and this is thought to be due to increased activation of signaling pathways

Correspondence to: Uma Sajjan, Department of Thoracic Surgery and Medicine, Temple University, 3500 N Broad Street, Philadelphia, PA 19140, USA, Tel: (215) 707-7139; Fax: (215) 707-4743; E-mail. uma.sajjan@temple.edu

Received: August 10, 2017; Accepted: September 04, 2017; Published: September 07, 2017 
downstream of TGF- $\beta 1[12,15]$. Furthermore, progenitor cells from COPD patients was shown to be defective in regenerating normal airway epithelium [16]. These observations indicate that airway progenitor cells in COPD may have acquired epigenetic changes due to persistent exposure to cigarette smoke and inflammatory milieu and these changes affect the regeneration of airway epithelium leading to abnormal airway epithelium.

Abnormality in airway epithelium in structure or function may significantly affect the outcome of infection. Previously, we demonstrated that compared to normal, mucociliary-differentiated COPD airway epithelial cell cultures show exaggerated chemokine responses and antiviral interferon responses [13]. Our on-going studies indicate that despite exaggerated antiviral responses COPD airway epithelial cell cultures show delay in clearing the virus and show enhanced goblet cell hyperplasia and pro-inflammatory phenotype after RV infection (Jing and Sajjan, unpublished observations). Several studies have shown similarly exaggerated chemokine responses to RV infection in cigarette smoke exposed normal airway epithelial cells indicating that cigarette smoke may be sufficient to alter the innate immune responses of these cells to infection $[17,18]$. Additionally RVinfected COPD cultures also show suppressed antimicrobial factor, human $\beta$ - defensin 2 to subsequent bacterial infection [19]. These findings indicate that COPD airway epithelial cells show aberrant innate immune responses to RV, and this may potentially recruit more neutrophils and other innate immune cells to the airways and increase respiratory symptoms in COPD. Consistent with this notion, experimental RV infection in mild COPD patients was accompanied by upper and lower respiratory symptoms that was more severe and prolonged compared to similarly-infected healthy non-smokers [20]. $\mathrm{RV}$ infection also increased oxidative and nitrosative stress markers in the lungs of COPD, but not in healthy subjects [21]. Further, this was shown to be due to reduced histone deacetylase 2 activity in macrophages. On a similar note, we showed that RV infection in mice with mild COPD phenotype resulted in persistent expression of CXCL1 expression, recruitment of neutrophils to the airways and sustained lung inflammation [22]. Further, studies are needed to understand the mechanisms of RV-induced exaggerated responses in COPD.

\section{Potential therapies for rhinovirus infection}

At present, there are no therapies to treat RV infection other than palliative therapies to treat symptoms of common colds. One of the reasons is that numerous serotypes of RV preclude the development of vaccines or any other specific therapies. Since RV-elaborated protease, $2 \mathrm{~A}, 3 \mathrm{C}$ plays a major role in $\mathrm{RV}$ replication, studies to develop treatment for RV are focused on inhibiting these proteases. Although some protease inhibitors have been shown to inhibit RV replication in vitro, their utilization as therapeutic agents is yet to be determined $[23,24]$. Recently, a1-antitrypsin that is expressed in the lungs and in other organs was shown to inhibit RV replication in vitro in airway epithelial cells and attenuate RV-induced neutrophilic inflammation in vivo [25]. This is quite promising since al-antitrypsin deficient subjects develop COPD-like lung disease and are vulnerable for RVinduced exacerbations [26]. Another potential therapy to treat RV infection is treatment with quercetin. Quercetin is a plant polyphenol with potent anti-inflammatory and antioxidant properties. We have previously demonstrated that quercetin interferes with various stages of viral life cycle, including viral entry, transcription and translation of viral genome, and processing of viral proteins [27]. Given the fact that quercetin also prevents progression of lung disease in COPD and modulates innate immunity of airway epithelial cells $[14,28]$, quercetin treatment may be useful in treating $\mathrm{RV}$-induced exacerbations in COPD.

\section{Conclusion}

Although COPD patients do not show increased frequency of RV infections, they experience more severe and prolonged respiratory symptoms. Following RV infection, COPD patients also acquire secondary bacterial infections leading to progression of lung disease. This may be due to defective innate immune mechanisms of COPD airway epithelial cells that line the conductive airways. Therefore, strategies that repairs the airway epithelium, improve innate immune mechanisms may reduce the impact of RV-induced severe respiratory symptoms and progression of lung disease in this patient population. Quercetin, which has the capacity to modulate airway innate immune functions and inhibit viral replication may be used for treating COPD exacerbations. Preliminary clinical trial indicate that quercetin is safely-tolerated up to $2000 \mathrm{mg} /$ day in COPD patients with mild to moderate lung disease (Han, Martinez and Sajjan, Unpublished results). However, further studies are required to establish the safety and efficacy of using quercetin as a therapy to treat COPD exacerbations.

\section{References}

1. Blaas D, Fuchs R2 (2016) Mechanism of human rhinovirus infections. Mol Cell Pediatr 3: 21. [Crossref]

2. Papi A, Bellettato CM, Braccioni F, Romagnoli M, Casolari P, et al. (2006) Infections and airway inflammation in chronic obstructive pulmonary disease severe exacerbations. Am J Respir Crit Care Med 173: 1114-1121. [Crossref]

3. Mallia P, Footitt J, Sotero R, Jepson A, Contoli M, et al. (2012) Rhinovirus Infection Induces Degradation of Antimicrobial Peptides and Secondary Bacterial Infection in COPD. Am J Respir Crit Care Med. 186: 1117-1124.

4. Palmenberg AC, Spiro D, Kuzmickas R, Wang S, Djikeng A, et al. (2009). Sequencing and analyses of all known human rhinovirus genomes reveal structure and evolution. Science 324: 55-59. [Crossref]

5. Staunton DE, Merluzzi VJ, Rothlein R, Barton R, Marlin SD, et al. (1989) A cell adhesion molecule, ICAM-1, is the major surface receptor for rhinoviruses. Cell 56 : 849-853. [Crossref]

6. Hofer F, Gruenberger M, Kowalski H, Machat H, Huettinger M, et al. (1994) Members of the low-density lipoprotein receptor family mediate cell entry of a minor-group common cold virus. Proc Natl Acad Sci U S A 91: 1839-1842. [Crossref]

7. Bochkov YA, Watters K, Ashraf S, Griggs TF, Devries MK, et al. (2015) Cadherinrelated family member 3 , a childhood asthma susceptibility gene product, mediates rhinovirus C binding and replication. Proc Natl Acad Sci U S A 112: 5485-5490. [Crossref]

8. Griggs TF, Bochkov YA, Basnet S, Pasic TR, Brockman-Schneider RA4, et al. (2017) Rhinovirus C targets ciliated airway epithelial cells. Respir Res 18: 84. [Crossref]

9. Mosser AG, Brockman-Schneider R, Amineva S, Burchell L, Sedgwick JB, et al. (2002) Similar frequency of rhinovirus-infectible cells in upper and lower airway epithelium. J Infect Dis 185: 734-743. [Crossref]

10. Faris AN, Ganesan S, Chattoraj A, Chattoraj SS, Comstock AT, et al. (2016) Rhinovirus Delays Cell Repolarization in a Model of Injured/Regenerating Human Airway Epithelium. Am J Respir Cell Mol Biol 55: 487-499. [Crossref]

11. Rock JR, Randell SH, Hogan BL (2010) Airway basal stem cells: a perspective on their roles in epithelial homeostasis and remodeling. Dis Model Mech 3: 545-556. [Crossref]

12. Milara J, Peiro T, Serrano A, Cortijo J (2013) Epithelial to mesenchymal transition is increased in patients with COPD and induced by cigarette smoke. Thorax 68: 410-420. [Crossref]

13. Schneider D, Ganesan S, Comstock AT, Meldrum CA, Mahidhara R, et al. (2010) Increased cytokine response of rhinovirus-infected airway epithelial cells in chronic obstructive pulmonary disease. Am J Respir Crit Care Med 182: 332-340. [Crossref]

14. Ganesan S, Unger BL, Comstock AT, Angel KA, Mancuso P, et al. (2013) Aberrantly activated EGFR contributes to enhanced IL-8 expression in COPD airways epithelial cells via regulation of nuclear FoxO3A. Thorax 68: 131-141. [Crossref] 
15. Mahmood MQ, Reid D, Ward C, Muller HK, Knight DA, et al. (2017) Transforming growth factor (TGF) $\hat{\mathrm{I}}^{2} 1$ and Smad signalling pathways: A likely key to EMT-associated COPD pathogenesis. Respirology 22: 133-140. [Crossref]

16. Staudt MR, Buro-Auriemma LJ, Walters MS, Salit J, Vincent T, et al. (2014) Airway Basal stem/progenitor cells have diminished capacity to regenerate airway epithelium in chronic obstructive pulmonary disease. Am J Respir Crit Care Med 190: 955-958. [Crossref]

17. Hudy MH, Traves SL, Proud D (2014) Transcriptional and epigenetic modulation of human rhinovirus-induced CXCL10 production by cigarette smoke. Am J Respir Cell Mol Biol 50: 571-582. [Crossref]

18. Hudy MH, Traves SL, Wiehler S, Proud D (2010) Cigarette smoke modulates rhinovirus-induced airway epithelial cell chemokine production. Eur Respir $J$ 35: 1256-1263. [Crossref]

19. Arnason JW1,2, Murphy JC2, Kooi C1,2, et al. (2017) Human $\hat{I}^{2}$-defensin-2 production upon viral and bacterial co-infection is attenuated in COPD. PLoS One 12: e0175963. [Crossref]

20. Mallia P, Message SD, Gielen V, Contoli M, Gray K, et al. (2011) Experimental rhinovirus infection as a human model of chronic obstructive pulmonary disease exacerbation. Am J Respir Crit Care Med 183: 734-742. [Crossref]

21. Footitt J, Mallia P, Durham AL, Ho WE, Trujillo-Torralbo MB, et al. (2016) Oxidative and Nitrosative Stress and Histone Deacetylase-2 Activity in Exacerbations of COPD. Chest 2016; 149: 62-73. [Crossref]
22. Ganesan S, Comstock AT, Kinker B, Mancuso P, Beck JM, et al. (2014) Combined exposure to cigarette smoke and nontypeable Haemophilus influenzae drives development of a COPD phenotype in mice. Respir Res 15: 11. [Crossref]

23. De Palma AM, Vliegen I, De Clercq E, Neyts J (2008) Selective inhibitors of picornavirus replication. Med Res Rev 28: 823-884. [Crossref]

24. 24. Bauer L, Lyoo H, van der Schaar HM, Strating JR, van Kuppeveld FJ [2017] Directacting antivirals and host-targeting strategies to combat enterovirus infections. Current opinion in virology 24: 1-8. [Crossref]

25. Berman R, Jiang D, Wu Q, Chu HW (2016) alpha1-Antitrypsin reduces rhinovirus infection in primary human airway epithelial cells exposed to cigarette smoke. Int $J$ Chron Obstruct Pulmon Dis 11: 1279-1286. [Crossref]

26. Kalfopoulos M, Wetmore K, K ElMallah M (2017) Pathophysiology of Alpha-1 Antitrypsin Lung Disease. Methods Mol Biol 1639: 9-19. [Crossref]

27. Ganesan S, Faris AN, Comstock AT, Wang Q, Nanua S, et al. (2012) Quercetin inhibits rhinovirus replication in vitro and in vivo. Antiviral Res 94: 258-271. [Crossref]

28. Ganesan S, Faris AN, Comstock AT, Chattoraj SS, Chattoraj A, et al. (2010) Quercetin prevents progression of disease in elastase/LPS-exposed mice by negatively regulating MMP expression. Respir Res 11: 131. [Crossref]

Copyright: (C2017 Owuor N. This is an open-access article distributed under the terms of the Creative Commons Attribution License, which permits unrestricted use, distribution, and reproduction in any medium, provided the original author and source are credited. 